\title{
SUPERALLOY 706 LARGE FORGINGS BY ESR
}

\author{
Takashi Shibata ${ }^{*}$, Tatsuya Takahashi *, Junichi Taira ${ }^{* *}$, and Terutaka Kure ${ }^{* *}$ \\ Muroran Research Laboratory ${ }^{*}$, Muroran Plant ${ }^{* *}$, \\ The Japan Steel Works, Ltd., \\ 4 Chatsu-machi, Muroran, Hokkaido 051-8505, Japan
}

\begin{abstract}
Alloy 706 is suitable for large forgings, but its precipitation behavior and mechanical properties are greatly affected by small differences in manufacturing factors. In this study, effects of each manufacturing factor on tensile properties of Alloy 706 were systematically investigated. As a result, it was clarified that tensile properties were determined by five factors: titanium content, niobium content, temperature and time of the 1st step in double aging treatment, and cooling rate from solution treatment. From the regressive analysis of this laboratory data, a prediction equation for tensile strength with the five factors was presented. Then, six large size trial disks were manufactured from VIM - ESR double-melted ingots with the five process parameters that were selected by using the prediction equation to give desired tensile properties. Tensile tests were performed with specimens taken from rim and core of the trial disks. The tensile strength of trial disks was in good agreement with that from obtained the prediction equation. The whole tensile properties were all acceptable for the specified value and were comparable to those from VIM ESR - VAR triple-melted ingot in literature.
\end{abstract}




\section{Introduction}

$\mathrm{Ni}-\mathrm{Fe}$-base superalloys are age-hardened by precipitation of coherent gamma prime and/or gamma double prime in the austenitic matrix gamma (1). Alloy 706 is a relatively new material and was developed from Alloy 718, a representative wrought superalloy. Compared with Alloy 718, Alloy 706 has a chemical composition of no molybdenum, reduced niobium, aluminum, chromium, nickel and carbon, and increased titanium and iron. This excellent balance of the alloying elements has brought the characteristics of Alloy 706 suoerior to those of Alloy 718 in segregation tendency, hot workability and machinability (2-4). Therefore, Alloy 706 is suitable for large forgings and has recently been used for land based turbines (5-6).

Alloy 706 is age-hardened by the coherent precipitation as same as other Ni-Fe-base superalloys, but its precipitation behavior is very complicated (7-9). In fact, the precipitation behavior of this alloy is largely affected by small differences in the manufacturing factors such as chemical composition and heat treatment condition, and so are mechanical properties accordingly (8-14). Therefore, in order to manufacture large forgings such as an industrial gas turbine disk, the manufacturing factors should be strictly controlled so as to achieve desirable mechanical properties.

This study will focus on the tensile property, as the most fundamental mechanical property of the large forgings. Firstly, effects of each manufacturing factor on tensile properties of Alloy 706 will be systematically exhibited. From these laboratory data, a prediction equation for tensile strength will be presented. The second half of this paper will deal with the tensile properties of the large size trial disks that were manufactured from double-melted ingot by utilizing this prediction equation, in order to confirm the validity of the equation. Furthermore, tensile properties and some other mechanical properties obtained in this study will be compared with the data in literature.

\section{Prediction of Tensile Properties}

\section{Procedure}

A typical manufacturing process of

Manufacturing

Process

Alloy 706 and manufacturing factors affecting the tensile properties are summarized in Figure 1. When any segregation does not exist and the grain size is uniform, the tensile properties of this alloy is considered to be detremined by chemical composition, solution treatment condition and aging treatment condition. Therefore, experimental alloys with various chemical compositions were heat treated at a wide variety of conditions.

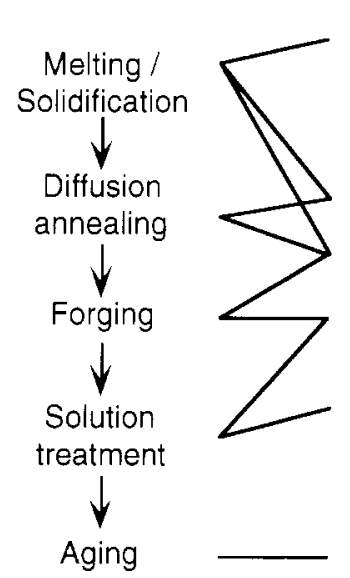

Chemical composition

- Amount of $\mathrm{Ti}, \mathrm{Nb}, \mathrm{Al}$ contents $\leftarrow \mathbf{X}_{\mathrm{Ti}}, \mathbf{X}_{\mathrm{Nb}}$

- Amount of $\mathrm{Fe}, \mathrm{Ni}$, Cr contents

- Amount of other elements

Segregation

Soldification structure

Grain size

Solution treatment condition

- Temperature / time

- Cooling rate after solution $\longleftarrow \mathbf{R}$

Aging condition

-1st stage temperature / time $\longleftarrow \mathbf{T}_{\mathbf{1}}, \mathbf{t}_{\mathbf{t}}$

-2nd stage temperature / time

Figure 1: Typical manufacturing process of Alloy 706 . 
Table I Chemical Compositions of Experimental Alloys

\begin{tabular}{ccccccccccccccc}
\hline No. & $\mathbf{N i}$ & $\mathbf{F e}$ & $\mathbf{C r}$ & $\mathbf{A l}$ & $\mathbf{T i}$ & $\mathbf{N b}$ & $\mathbf{C}$ & $\mathbf{N}$ & $\mathbf{O}$ & $\mathbf{B}$ & $\mathbf{S i}$ & $\mathbf{M n}$ & $\mathbf{P}$ & $\mathbf{S}$ \\
\hline 1 & $\mathbf{4 2 . 8 0}$ & bal. & $\mathbf{1 6 . 1 8}$ & $\mathbf{0 . 2 5}$ & $\mathbf{1 . 6 8}$ & $\mathbf{2 . 8 5}$ & $\mathbf{0 . 0 0 6}$ & $\mathbf{0 . 0 0 4 1}$ & $\mathbf{0 . 0 0 0 6}$ & $\mathbf{0 . 0 0 4 8}$ & $\mathbf{0 . 0 2}$ & $\mathbf{0 . 0 2}$ & $<\mathbf{0 . 0 0 3}$ & $<\mathbf{0 . 0 0 0 5}$ \\
\hline 2 & 41.80 & bal. & 16.40 & $\mathbf{0 . 2 8}$ & $\mathbf{2 . 0 2}$ & $\mathbf{2 . 5 3}$ & 0.005 & 0.0014 & 0.0024 & 0.0012 & 0.01 & 0.01 & $<0.003$ & 0.0008 \\
\hline 3 & 41.94 & bal. & 16.56 & $\mathbf{0 . 2 8}$ & $\mathbf{1 . 5 2}$ & $\mathbf{3 . 2 7}$ & 0.004 & 0.0019 & 0.0027 & 0.0015 & 0.01 & 0.01 & $<0.003$ & 0.0009 \\
\hline 4 & 43.44 & bal. & 16.52 & $\mathbf{0 . 3 0}$ & $\mathbf{1 . 5 3}$ & $\mathbf{2 . 5 2}$ & 0.006 & 0.0018 & 0.0016 & 0.0015 & 0.01 & 0.01 & $<0.003$ & 0.0008 \\
\hline 5 & 43.64 & bal. & 16.27 & $\mathbf{0 . 2 5}$ & $\mathbf{1 . 7 8}$ & $\mathbf{2 . 8 7}$ & $<0.003$ & 0.0024 & 0.0019 & 0.0005 & 0.01 & 0.01 & $<0.003$ & 0.0011 \\
\hline 6 & 43.62 & bal. & 16.13 & $\mathbf{0 . 0 5}$ & $\mathbf{1 . 7 5}$ & $\mathbf{2 . 8 2}$ & $<0.003$ & 0.0026 & 0.0025 & 0.0005 & 0.04 & 0.01 & $<0.003$ & 0.0009 \\
\hline
\end{tabular}

Six heats of experimental alloys were melted in a $50 \mathrm{~kg}$ vacuum induction melting (VIM) furnace. The chemical compositions of the alloys are listed in Table I. Alloy No.1 has the nominal composition of Alloy 706. Nos. $2 \sim 6$ have different content of strengthening elements, aluminum, titanium and niobium, that are within the specified range in the AMS $5701 \sim 5703$. All ingots were diffusion-treated and subsequently forged to billets. These billets were mechanically sectioned into samples of suitable sizes for the following experiments.

The heat treatment conditions used in this study are summarized in Figure 2. All samples were solution-treated at $980^{\circ} \mathrm{C}$ for $3 \mathrm{~h}$, so as to fully dissolve precipitates formed in the forging process and to obtain a mean grain size of ASTM \#3-4. Cooling rate after the solution treatment was varied from 0.5 to $85^{\circ} \mathrm{C} / \mathrm{min}$. Subsequently, they were double-

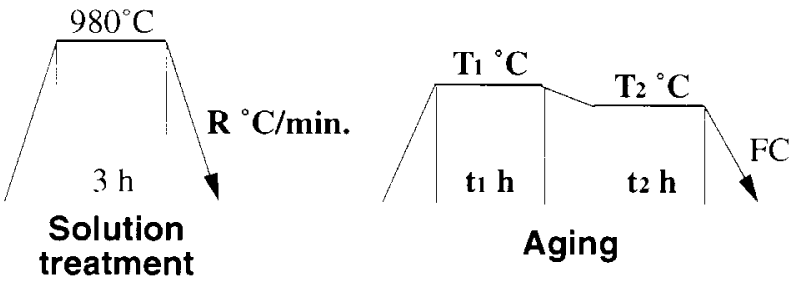
$\mathrm{R}=0.5 \sim 85^{\circ} \mathrm{C} / \mathrm{min}$ $\begin{array}{ll}\mathrm{T}_{1}=720 \sim 740{ }^{\circ} \mathrm{C} & \mathrm{T}_{2}=620 \sim 640^{\circ} \mathrm{C} \\ \mathrm{t}_{1}=8 \sim 16 \mathrm{~h} & \mathrm{t}_{2}=8 \sim 16 \mathrm{~h}\end{array}$ aged at $720 \sim 740{ }^{\circ} \mathrm{C}$ for $8 \sim 16 \mathrm{~h}$ and at $620 \sim 640$ ${ }^{\circ} \mathrm{C}$ for $8 \sim 16 \mathrm{~h}$.

Figure 2: Heat treatment conditions.

All the samples heat-treated at various conditions were subjected to tensile tests at room temperature. The diameter of specimens was $7 \mathrm{~mm}$ and the gauge length was $30 \mathrm{~mm}$. While detailed investigation of precipitation behavior was also conducted by transmission electron microscopy (TEM), its result will be presented elsewhere because of limitations of space.

\section{Effect of Chemical Composition}

Figure 3 shows the effects of titanium, niobium and aluminum contents on the tensile properties of Alloy 706. The cooling rate from solution treatment was fixed at $10{ }^{\circ} \mathrm{C} / \mathrm{min}$ and the double-aging condition was also fixed at $720^{\circ} \mathrm{C}$ for $8 \mathrm{~h}$ and at $620^{\circ} \mathrm{C}$ for $8 \mathrm{~h}$. Tensile strength and $0.2 \%$ yield strength increased, whereas elongation and reduction of area decreased, as the content of strengthening element is increased within the specified range.

However, the influence of aluminum content on the tensile properties was much smaller than that of titanium content or niobium content. This difference is considered to reflect the change in the lattice mis- 


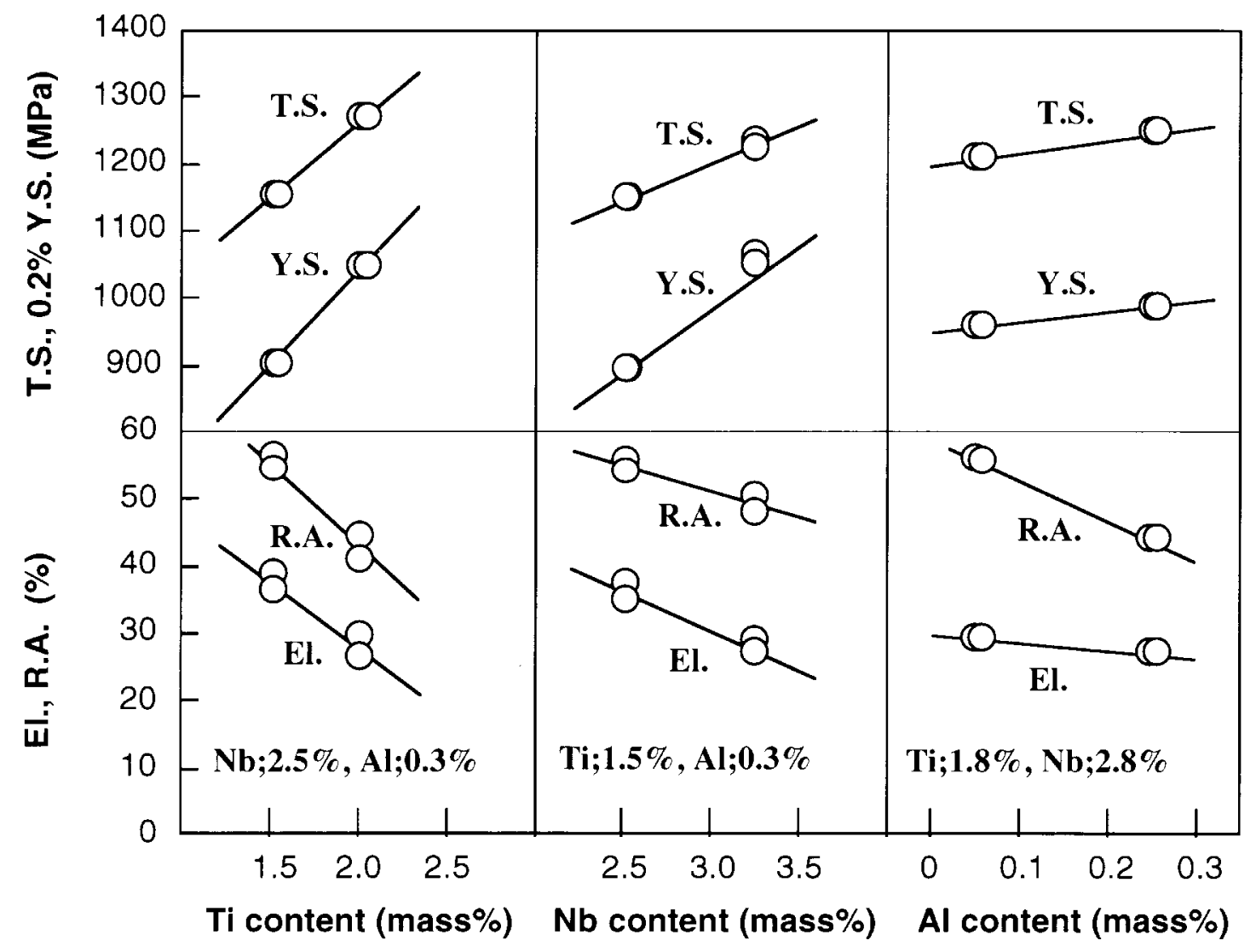

Figure 3: Variation of the tensile properties with $\mathrm{Ti}, \mathrm{Nb}$ and $\mathrm{Al}$ contents.

match between strengthening precipitates and matrix. Because the strengthening ability of gamma double prime is greater than that of gamma prime, aluminum which mainly forms gamma prime does not significantly affect the tensile properties. In contrast to aluminum, niobium tends to form gamma double prime and titanium can form both gamma prime and gamma double prime $(1,7)$.

As described above, strength of Alloy 706 increased and ductility decreased as content of any strengthening element was increased in the specified range. Evaluated tensile properties were acceptable for the specified range of AMS 5701, except for alloy No.4 with the lowest value for both titanium and niobium content. Therefore, in order to satisfy the specified tensile properties, titanium and niobium content should not simultaneously be low, even in the specified range of chemical composition.

\section{Effect of Aging Condition}

Figure 4 shows the effect of the aging temperature on the tensile properties with constant aging time of 8 h. The horizontal axis is the temperature of the 1 st step in double aging treatment, and the temperature of the 2 nd step is distinguished by the symbol. For every aging condition, strength increased and ductility decreased, with increasing the 1 st step temperature. On the contrary, the 2 nd step temperature shows no significant effect on tensile properties. Therefore, it was found that the influence of the 1st step temperature on tensile properties was remarkably greater than that of 2 nd step temperature. 


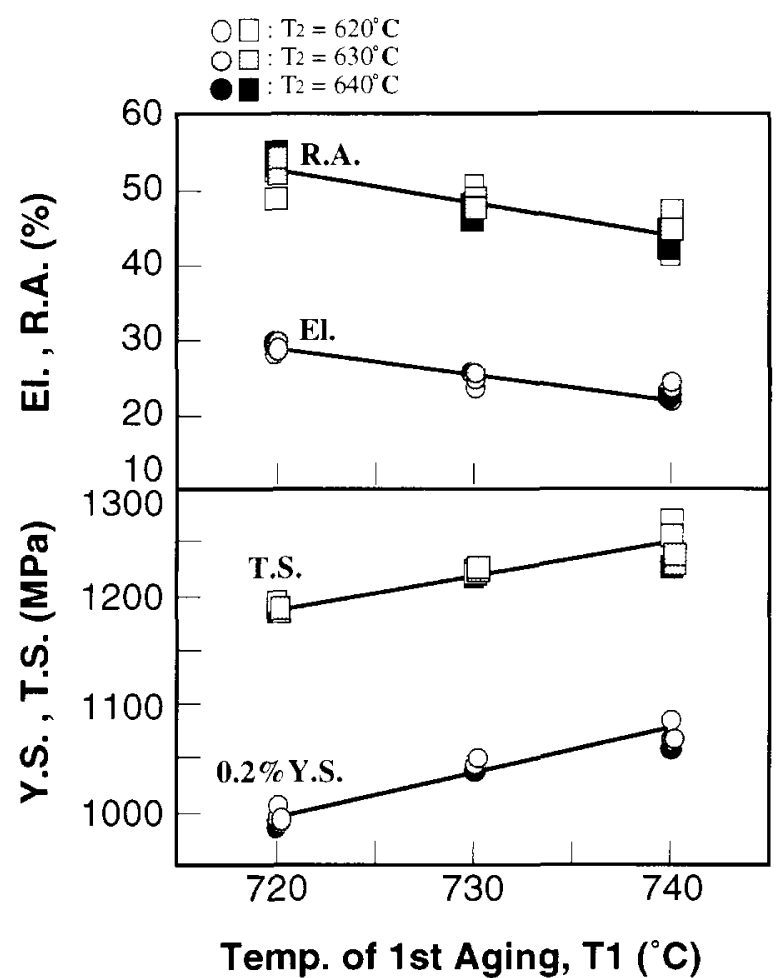

Figure 4: Variation of the tensile properties with aging temperature.

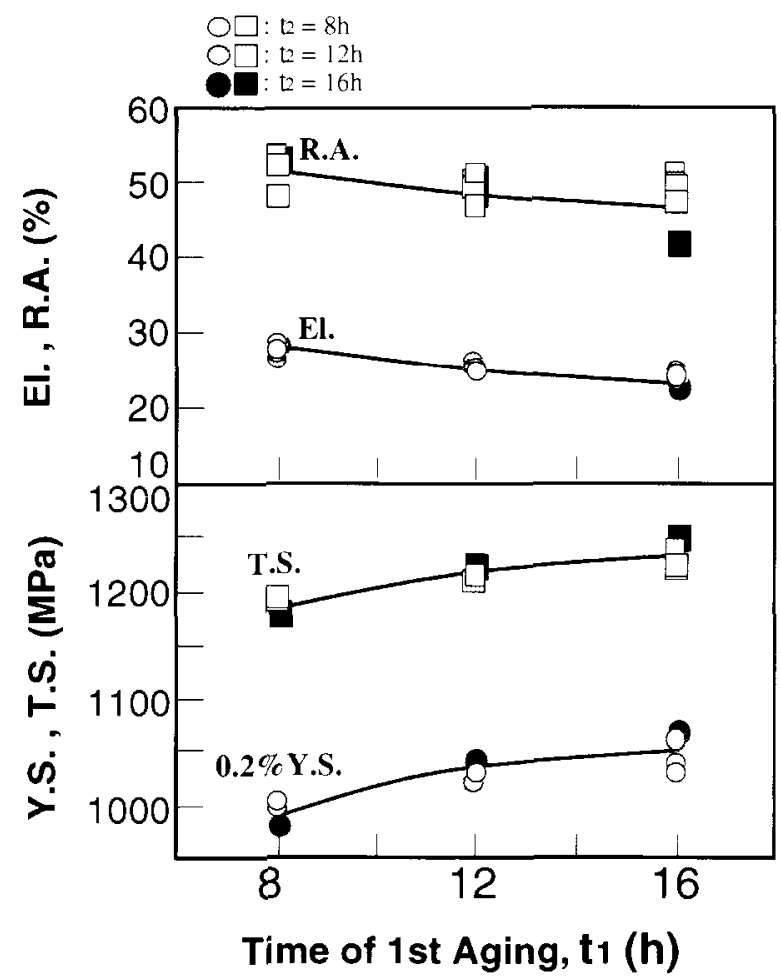

Figure 5: Variation of the tensile properties with aging time.

The effect of aging time on the tensile properties with fixed aging temperature of $720{ }^{\circ} \mathrm{C}$ for the 1 st step and $620^{\circ} \mathrm{C}$ for the 2 nd step is shown in Figure 5. The horizontal axis is the time of the 1st step in double aging treatment, and the time of the 2 nd step is distinguished by the symbol. While the strength increased and the ductility decreased for every aging condition with increasing the 1 st step time, the 2 nd step time indicated almost no effect on the tensile properties. Therefore, it is obvious that the influence of the $1 \mathrm{st}$ step aging time on the tensile properties is remarkably greater than that of the 2 nd step time.

As mentioned above, the tensile properties of Alloy 706 were predominantly affected by the aging condition of the 1 st step in double aging treatment, and was hardly affected by the condition of the 2 nd step. For the aging condition of the 1 st step, the change in tensile properties with temperature varied from $720^{\circ} \mathrm{C}$ to $740^{\circ} \mathrm{C}$ was larger than that with time from $8 \mathrm{~h}$ to $16 \mathrm{~h}$. Hence, aging temperature is more effective than aging time, from the industrial point of view.

From this experiment, only to get satisfactory tensile properties, the 2 nd step in double aging treatment may be omitted. However, in the case of large forgings, temperature difference originated in mass effect may cause the difference in aging temperature / time between surface and center, resulting in the deviation of mechanical properties. From this point of view, the 2 nd step can be regarded as the equalizing heat treatment in the cooling stage from the aging treatment, so there is a possibility that the 2 nd step is industrially beneficial, especially in the case of large forgings. 
The tensile properties showed a complicated variation with change in the cooling rate from solution treatment, as seen in Figure 6. Strength increased as the cooling rate decreased from $85^{\circ} \mathrm{C} / \mathrm{min}$ down to $3{ }^{\circ} \mathrm{C} / \mathrm{min}$, and then was maximized at about $3{ }^{\circ} \mathrm{C} / \mathrm{min}$. Strength, however, conversely decreased with decreasing the cooling rate below $3{ }^{\circ} \mathrm{C} / \mathrm{min}$. On the contrary, ductility gradually decreased as the cooling rate decreased down to $10{ }^{\circ} \mathrm{C} /$ min, and decreased more rapidly in the range from 10 to $5^{\circ} \mathrm{C} / \mathrm{min}$. Then, the ductility again gradually decreased as the cooling rate decreased below $5^{\circ} \mathrm{C} / \mathrm{min}$.

As these facts indicate, the tensile properties of Alloy 706 is greatly affected by the cooling rate from solution treatment, and it is important to select proper cooling rate to obtain desired tensile properties. Since both strength and ductility are degraded when the cooling rate is lower than $3{ }^{\circ} \mathrm{C} / \mathrm{min}$ at which the tensile strength shows maximum, the cooling rate

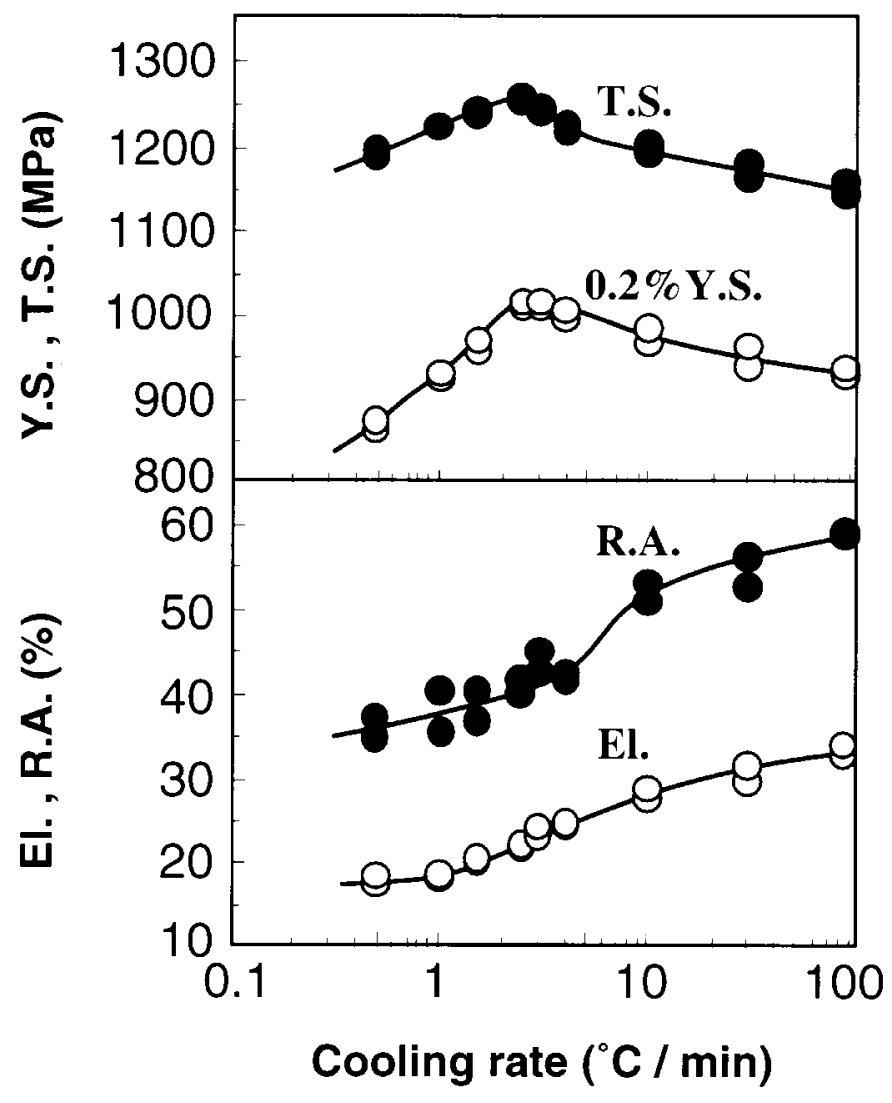

Figure 6: Variation of the tensile properties with the cooling rate from solution treatment. below $3{ }^{\circ} \mathrm{C} / \mathrm{min}$ should not be adopted from the practical point of view.

These complicated changes are due to the complicated precipitation behavior of Alloy 706. Precipitation occurs relatively rapidly in this alloy, so the inevitable precipitation that occurs in the cooling stage in solution treatment has a strong influence on the precipitation behavior even after aging treatment (9). In other words, the final precipitation behavior of this alloy is determined by both the cooling condition from solution temperature and the aging treatment condition, not only by the aging treatment condition. In addition to this, thermal conductivity of $\mathrm{Ni}$-Fe based superalloy is generally lower than that of popular ferrous alloys. Therefore, particularly for large forgings, the cooling rate at the mid-thickness portion is very much lower than that near the surface and this difference inevitably causes tensile property variation.

\section{Prediction of Tensile Property from Manufacturing Factors}

Figure 7 shows the relationships between tensile strength and $0.2 \%$ yield strength, elongation, and reduction of area. Each relation as a function of tensile strength can be regarded as straight line having only a little scattering. Therefore, prediction of tensile strength can lead to the whole tensile properties. 
From the experiments mentioned above, it was clarified that the dominant manufacturing factors affecting the tensile properties of Alloy 706 were following five factors: titanium content, niobium content, temperature and time of the 1 st step in double aging treatment, and the cooling rate from solution treatment. Then, all the tensile property data given in the laboratory scale experiment was examined by using the regressive analysis. For the cooling rate from solution treatment, only the data within faster range than the point at which tensile strength showed a maximum was used from the practical aspect.

As a result, the tensile strength was represented by the following equation,

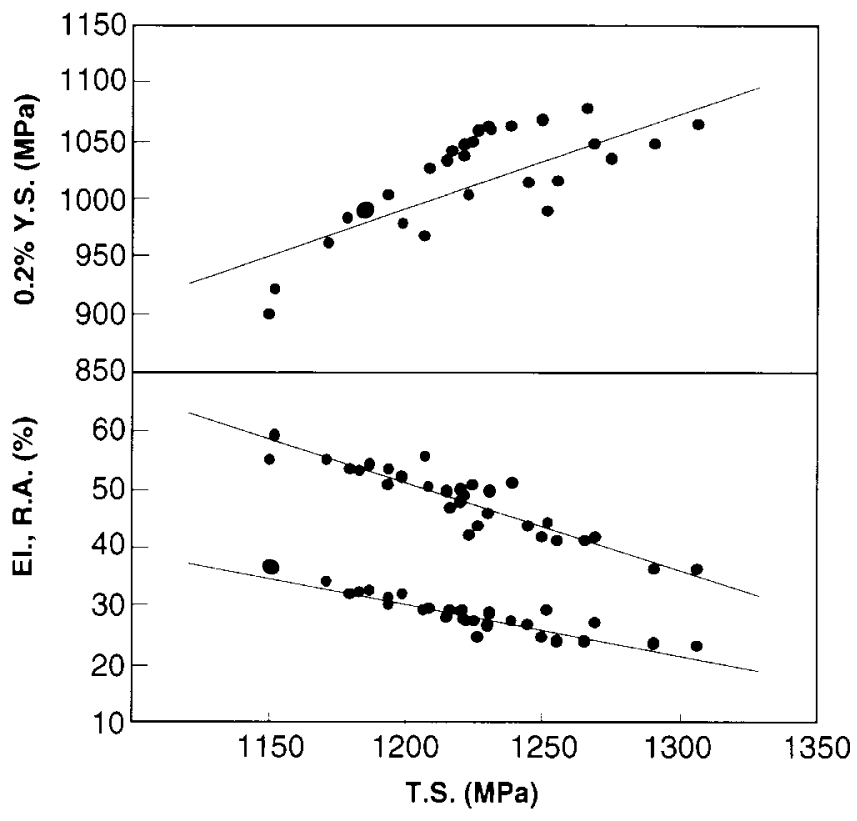

Figure 7: The relationships between tensile strength and $0.2 \%$ yield strength, elongation, and reduction of area.

$$
\text { T.S. }=137 \mathrm{X}_{\mathrm{Ti}}+46 \mathrm{X}_{\mathrm{Nb}}-0.38 \mathrm{R}+2.4 \mathrm{~T}_{1}+6.3 \mathrm{t}_{1}-943
$$

where, T.S.: tensile strength (MPa), $\mathrm{X}_{\mathrm{Ti}}$ : titanium content $(\mathrm{wt} \%), \mathrm{X}_{\mathrm{N}}$ : niobium content $(\mathrm{wt} \%), \mathrm{R}$ : cooling rate from solution treatment $\left({ }^{\circ} \mathrm{C} / \mathrm{min}\right), \mathrm{T}_{1}$ : temperature of the 1 st step in double aging treatment $\left({ }^{\circ} \mathrm{C}\right), \mathrm{t}_{1}$ : time of the 1 st step in double aging treatment $(\mathrm{h})$.

The relationship between measured value and calculated value by using this prediction equation is shown in Figure 8. All tensile strength data obtained in the laboratory scale experiment were plotted. Measured value shows a good straightlined relationship with calculated value. Therefore, through tensile strength, other three tensile properties, $0.2 \%$ yield strength, elongation and reduction of area, can also be predicted by the equation with the five manufacturing factors. In other words, the manufacturing factors to attain the desirable tensile properties can be decided by using the prediction equation.

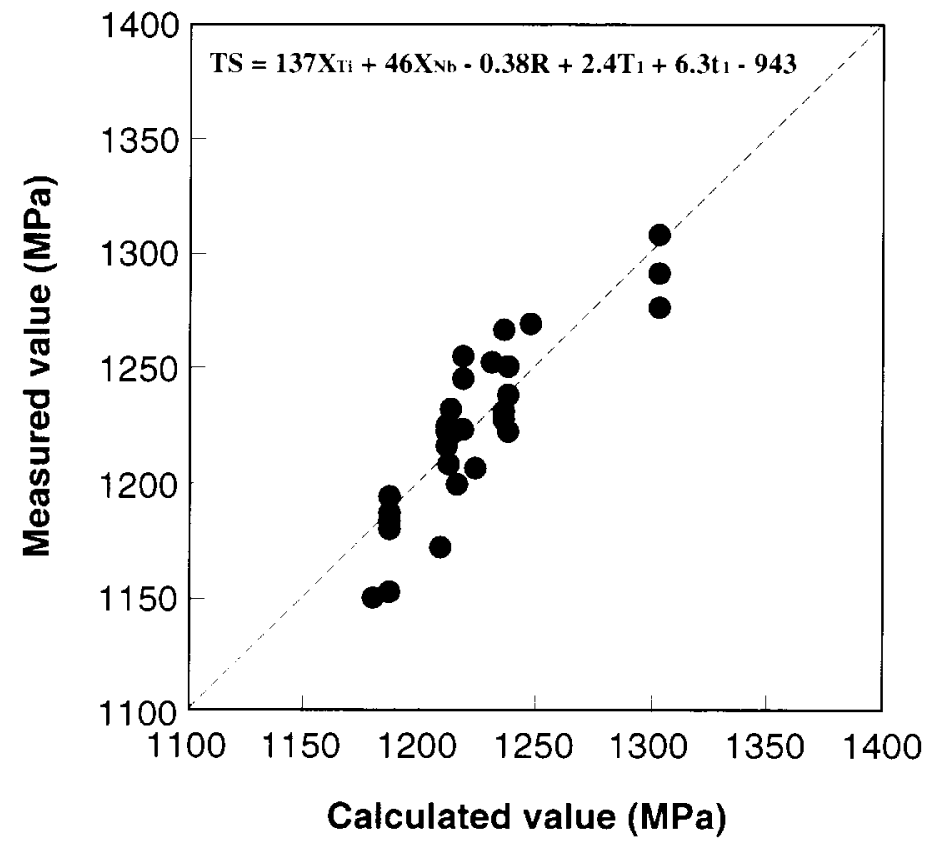

Figure 8: Comparision between calculated and measured tensile strength value. 


\section{Trial Manufacture of Large Size Disks}

\section{Procedure of trial manufacture}

The six trial disks with pancake-shape were manufactured. Their diameters were up to $1500 \mathrm{~mm}$ and their thicknesses were up to $250 \mathrm{~mm}$. The aim of this manufacture was that tensile properties of any portion of every disk were acceptable for specified tensile properties in AMS 5703 (TS : $1170 \mathrm{MPa}, 0.2 \%$ YS : 930 $\mathrm{MPa}$, El. : 12\%, R.A. : 15\%).

The ingots were made by vacuum induction melting (VIM) followed by electroslag remelting (ESR). For making ingots, titanium content and niobium content in the prediction equation must be selected in order to obtain desirable tensile properties. As described before, the higher the contents both of titanium and niobium are, the higher is the tensile strength. However, these elements are known to promote the segregation in ingot. In this study, therefore, titanium and niobium contents were controlled in the range of 1.6 $\sim 1.8 \mathrm{wt} \%$ and $2.8 \sim 3.0 \mathrm{wt} \%$, respectively, considering the balance of strength and segregation. Contents of the other elements were aimed to the center of the specified range. More precise information of ingot making will be described elsewhere in this proceedings.

All ingots were diffusion treated and subsequently forged to desirable shape. Since Ni-Fe based superalloys have a stable gamma phase and do not transform, grain refining by transforming recrystallization can not be expected. Then, forging process was optimized in terms of compressibility and recrystallization temperature / time, particularly in the final forging stage.

In order to ontain desirable tensile property, conditions of solution treatment and aging treatment must be properly decided. In this study, temperature of solution treatment was constant of $980^{\circ} \mathrm{C}$, and the doubleaging condition was also constant, at $720^{\circ} \mathrm{C}$ for $8 \mathrm{~h}$ and at $620^{\circ} \mathrm{C}$ for $8 \mathrm{~h}$. Only for the desired tensile properties, the 2 nd step in double aging treatment may be omitted, as mentioned before. In this study, however, the 2 nd step was adopted as the equalizing heat treatment in the cooling stage from the 1 st step.

The remaining and the most important factor is the cooling rate from solution treatment. As described before, the cooling rate in the range between 5 and $30^{\circ} \mathrm{C} / \mathrm{min}$ is preferable, considering the balance of both strength and ductility. Then, for various cooling methods, the cooling rate of each disk was calculated by FEM analysis. From this analysis, the cooling method was selected so that the cooling rate of the whole forgings was within the appropriate range. Generally speaking, water quench was adopted for large disk and air-cooling was adopted for small disk. Fine controlling of cooling rate was achieved by special techniques.

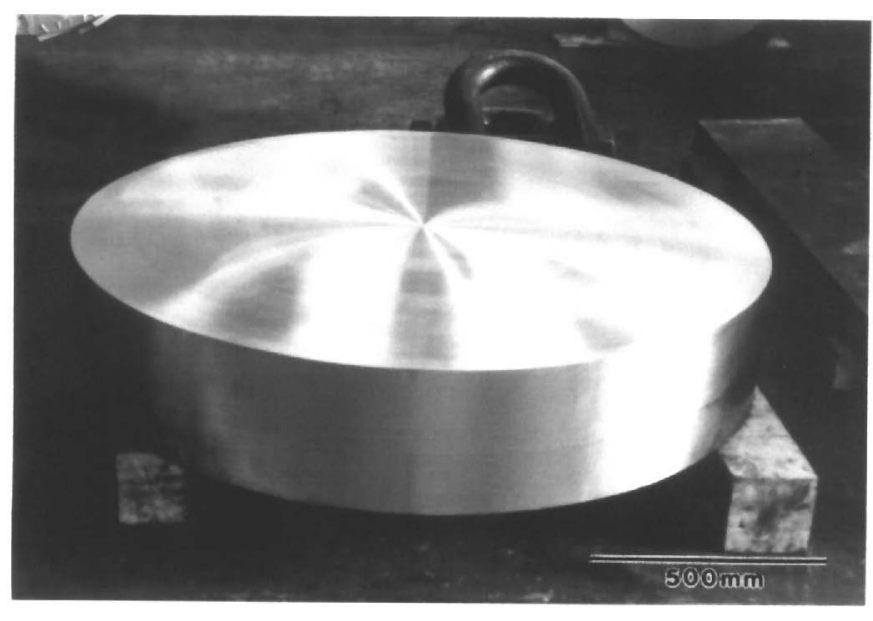

Figure 9: Typical examle of the trial disk. 
A typical example of the trial disk is shown in Fiure 9. The macro-etching structures of the whole surface of disks and core samples taken from the center portions revealed that no segregation existed in all disks. Chemical compositions at various portions in the disks were within the aimed range, but were slightly varied by each heat. For all disks, grain sizes were in the range from ASTM $\# 3$ to \#4 in the whole of the disks.

Figures 10 and 11 show typical scanning electron micrograph and typical transmission electron micrograph, respectively. These specimens were taken from the rim and the core portion of the trial disks. Precipitation behavior inside a grain and at a grain boundary varied, mainly because of the difference in the cooling rate from solution treatment between the rim and the core.

This variation was consistent with the estimation from the other fundamental studies (7-9). That is, strengthening precipitates inside a grain were two types of gamma prime - gamma double prime coprecipitate which were peculiar in Alloy 706. Over-laid type co-precipitate was dominant at the rim portion with higher cooling rate and double cuboidal type co-precipitate simultaneously existed at the core portion with lower cooling rate. At the core portion, eta phase also precipitated at a grain boundary.

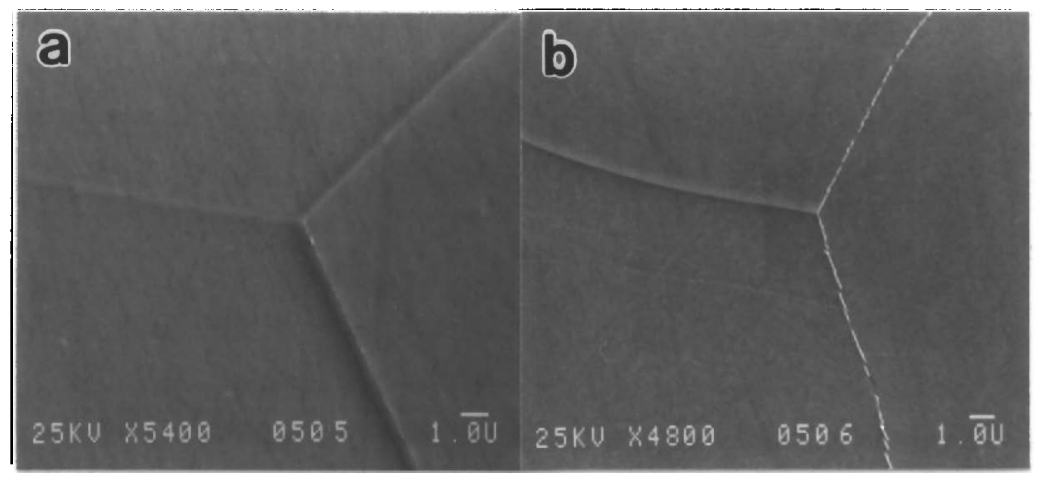

Figure 10: Typical example of scanning electoron micrographs of the trial disk. (a) Rim (b) Core.

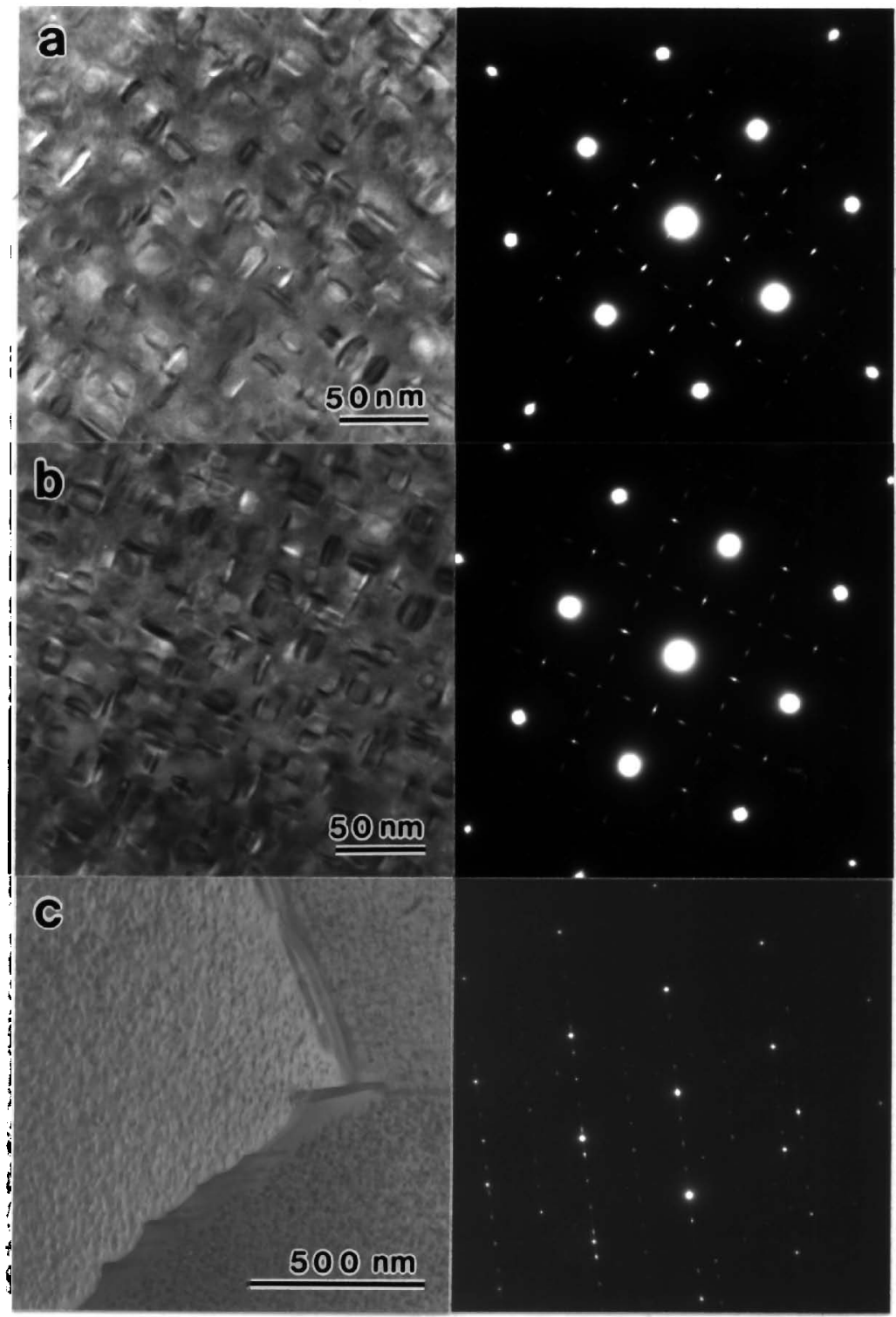

Figure 11: Typical example of transmission electoron micrographs of the trial disk. (a) Rim (b) Core (c) Core. 
Tensile tests were performed at room temperature using specimens taken from the rim and core of the six trial disks. Figure 12 shows a comparison of the tensile strength of measured and calculated by the prediction equation. The measured values of trial disks are in good agreement with the calculated values, while there is some extent of scattering, as seen in Figure 12. Tensile strength of the trial disks was all acceptable for the specified value, and the other tensile properties, $0.2 \%$ yield strength, elongation and reduction of area, were also acceptable. Therefore, Alloy 706 large forgings with desirable tensile properties can be manufactured by using this prediction equation.

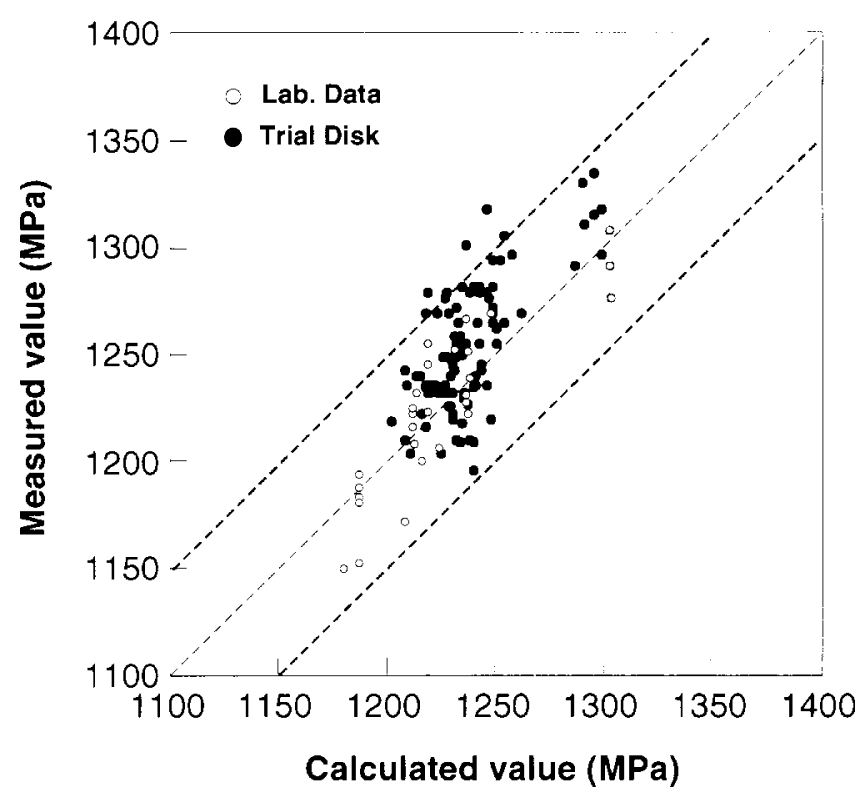

Figure 12: Comparison of the tensile strength measured and calculated by the prediction equation.

\section{Comparison with the Data in Literature}

Comparison of tensile properties in this study with those in literature with respect to triple melted ingots $(5,15)$ are summarized in Figure 13. As shown in this figure, tensile properties of 706 from doublemelted ingot are all acceptable for the specified value, and are well comparable to those from triple-melted ingot. It should be noted that the ductility of 706 from doublemelted ingot are higher rather than that from triple-melted ingot. This seems to be due to the difference of ingot size and/or some difference in chemical composition, but the substantial reason has not been well understood at this moment.
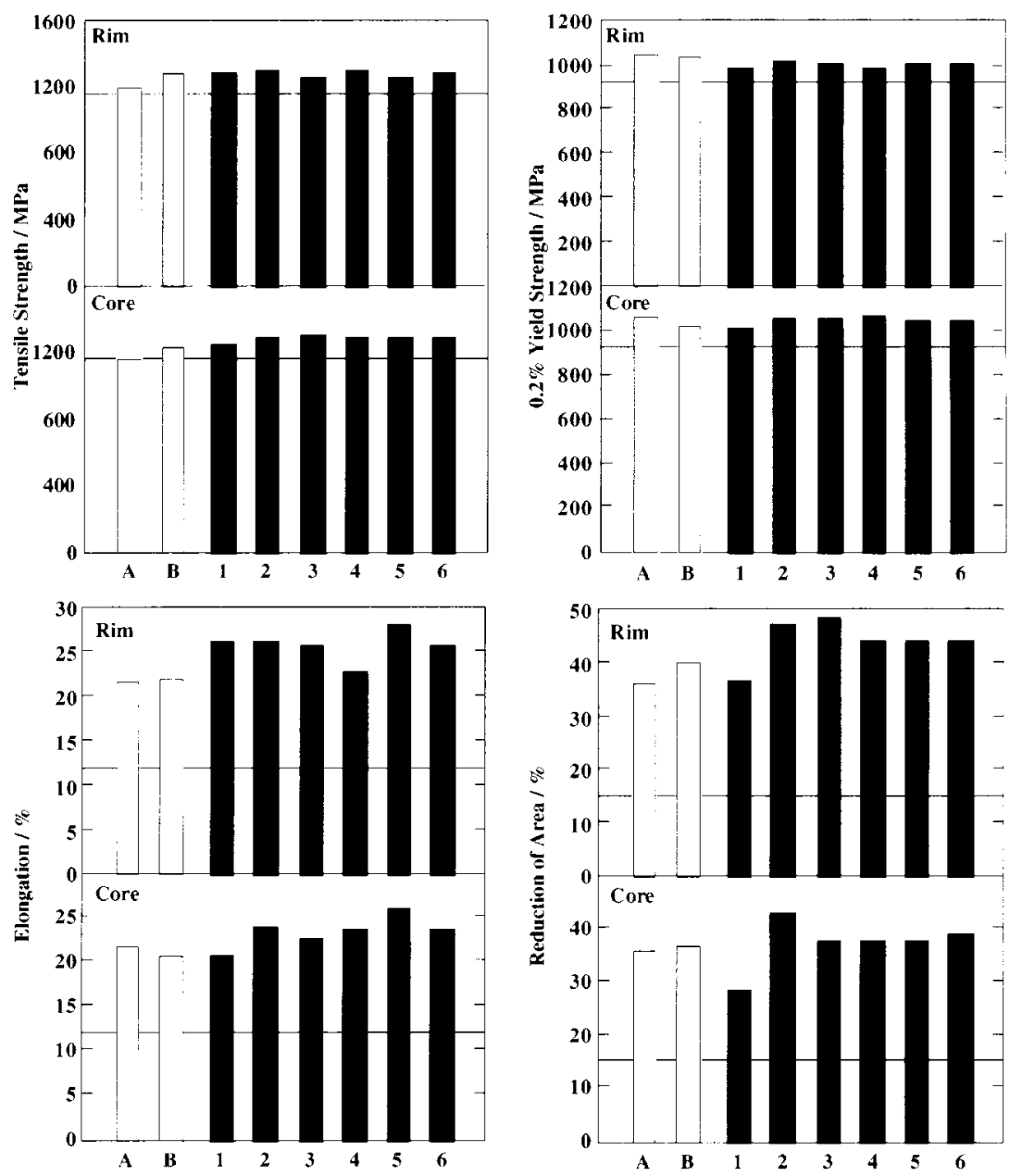

Figure 13: Comparison of tensile properties in this study with the data in literature; Nos.A \& B in literature (5) and (15) respectivly and Nos. $1 \sim 6$ in this study. 
Table II Hot tensile properties : (A) at rim and (B) at core

(A)

\begin{tabular}{|r|r|r|r|r|}
\hline T/deg. C & T.S. $/ \mathrm{MPa}$ & Y.S. $/ \mathrm{MPa}$ & El. $/ \%$ & R.A. $/ \%$ \\
\hline 400 & 1108 & 892 & 19.2 & 54.8 \\
\hline 480 & 1080 & 864 & 20.8 & 57.0 \\
\hline
\end{tabular}

(B)

\begin{tabular}{|r|r|r|r|r|}
\hline T/deg. C & T.S. $/ \mathrm{MPa}$ & Y.S. $/ \mathrm{MPa}$ & \multicolumn{1}{|c|}{ El. $\%$} & R.A. $/ \%$ \\
\hline 400 & 1119 & 934 & 18.4 & 48.2 \\
\hline 480 & 1081 & 884 & 22.4 & 57.0 \\
\hline
\end{tabular}

Figure 14 shows the comparison of low cycle fatigue property of double-melted 706 with that of triple-melted 706 . Low cycle fatigue test was performed with total strain range of 0.7 $\%$, frequency of $20 \mathrm{CPM}$, strain rate of $28 \% / \mathrm{min}$., and A-ratio of 1 . Low cycle fatigue property of double-melted 706 is also comparable to triple-melted 706, as shown in Figure 14. Other properties are summarized in Table II, and those are considered to be satisfactory for Alloy 706 .

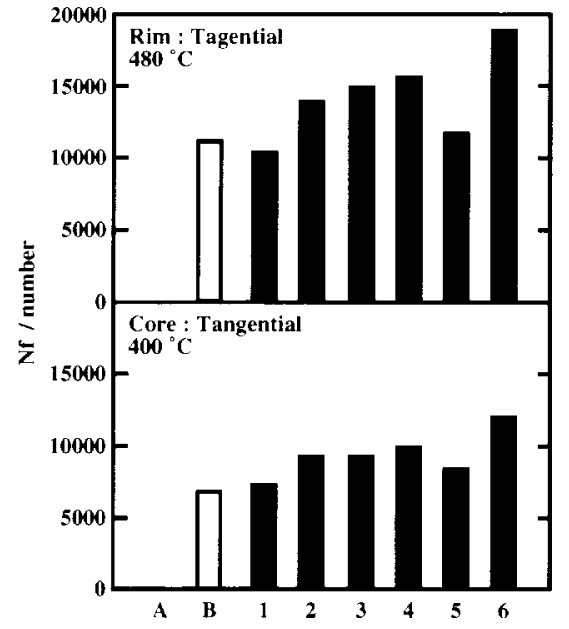

Figure 14: Comparison of low cycle fatigue property in this study with the data in literature; No. B in literature (15) and Nos. $1 \sim 6$ in this study.

Therefore, it can be concluded that 706 large forgings with desirable mechanical property is obtained by means of the appropriate consideration to manufacturing process, even from the double-melted ingot.

\section{Conclusions}

In order to assist in manufacturing of Alloy 706 large forgings, the prediction method of tensile property, that is the most fundamental mechanical property, was investigated in detail. Then, the large size trial disks were manufactured by using the prediction equation on the tensile strength, to confirm the validity. As a result, the following conclusions can be drawn:

1. The prediction of tensile strength can lead to the whole tensile properies. With five dominant manufacturing factors affecting the tensile properties of Alloy 706 , tensile strength is represented by the following equation,

$$
\text { T.S. }=137 \mathrm{X}_{\mathrm{Ti}}+46 \mathrm{X}_{\mathrm{Nb}}-0.38 \mathrm{R}+2.4 \mathrm{~T}_{1}+6.3 \mathrm{t}_{1}-943
$$

where, TS: tensile strength (MPa), $\mathrm{X}_{\mathrm{Ti}}$ : titanium content (wt \%), $\mathrm{X}_{\mathrm{Nb}}$ : niobium content (wt \%), R: cooling rate from solution treatment $\left({ }^{\circ} \mathrm{C} / \mathrm{min}\right), \mathrm{T}_{1}$ : temperature of the 1 st step in double aging treatment $\left({ }^{\circ} \mathrm{C}\right), \mathrm{t}_{1}$ : time of the 1 st step in double aging treatment $(\mathrm{h})$.

2. The measured tensile strength of trial disks is in good agreement with the calculated one from the prediction equation, and is all acceptable for the specified tensile property. Therefore, it is made possible to manufacture Alloy 706 large forgings with desirable tensile properties by the prediction equation obtained in this study. 


\section{REFERENCES}

(1) E.E.Brown and D.R.Muzyka, "Nickel-Iron Alloys", Superalloys II, ed. by C.T.Sims et.al., (New York, John Wiley \& Sons, 1987), P165.

(2) H.L.Eiselstein, "Properties of Inconel Alloy 706", ASM Technical Report, No.C 70-9.5, (1970), P1.

(3) H.L.Eiselstein, "Properties of a Fabricable, High Strength Superalloy", Metals Engineering Quarterly, November(1971), P20.

(4) E.L.Raymond and D.A.Wells, "Effects of Aluminum Content and Heat Treatment on Gamma Prime Structure and Yield Strength of Inconel Nickel-Chromium Alloy 706", Proceedings of the 2nd International Conference on Superalloys - Processing (Columbus, Metals and Ceramics Information Center, 1972), N1.

(5) P.W.Schilke, J.J.Pepe and R.C.Schwant, "Alloy 706 Metallurgy and Turbine Wheel Application", Proceedings of the International Symposium on Superalloys 718,625,706 and Various Derivatives, (ed. by E.A.Loria, Pittuburgh, TMS, 1994), P1.

(6) A.D.Helms, C.B.Adasczik and L.A.Jackman, "Extending the Size LIMITS of Cast/Wrought Superalloy Ingots", Superalloys 1996 (ed. by, R.D.Kissinger et al., Warrendale, PA:TMS, 1996), P427.

(7) T. Shibata, Y. Shudo and Y. Yoshino, "Effects of Aluminum, Titanium and Niobium on the Time Temperature - Precipitation Behavior of Alloy 706", ibid., P153.

(8) T.Shibata et al., "Effect of Stabilizing Treatment on Precipitation Behavior of Alloy 706", ibid., P627.

(9) T.Shibata et al., "Effect of Cooling Rate from Solution Treatment on Precipitation Behavior and Mechanical Properties of Alloy 706", Proceedings of the International Symposium on Superalloys 718,625,706 and Various Derivatives (ed. by, E.A.Loria, Pittuburgh, TMS, 1997), P379.

(10) J.H.Moll, G.N.Maniar and D.R.Muzyka, "The Microstructure of 706, a New Fe-Ni-Base Superalloy", Met. Trans., 2(1971), P2143.

(11) J.H.Moll, G.N.Maniar and D.R.Muzyka, "Heat Treatment of 706 Alloy for Optimum $1200^{\circ}$ F StressRupture Properties", ibid., P2153.

(12) L.Remy, J.Laniesse and H.Aubert, "Precipitation Behavior and Creep Rupture of 706 Type Alloys", Materials Science and Engineering, 38(1979), P227.

(13) G.W.Kuhlman et al., "Microstructure - Mechanical Properties Relationships in Inconel 706 Superalloy", Proceedings of the International Symposium on Superalloys 718,625.706 and Various Derivatives (ed. by, E.A.Loria, Pittuburgh, TMS, 1994), P441.

(14) T.Takahashi et al., "Effects of Grain Boundary Precipitation on Creep Rupture Properties of Alloy 706 and 718 Turbine Disk Forgings", ibid., P557.

(15) P.Petit and J.P.Fesland, "Manufacturing of Large IN 706 and IN 718 Forging Parts", Proceedings of the International Symposium on Superalloys 718.625,706 and Various Derivatives (ed. by, E.A.Loria, Pittuburgh, TMS, 1997), P153. 